\title{
Functional soil organic matter fractions in response to long-term fertilization in upland and paddy systems in South China
}

\author{
Fan Yang ${ }^{\mathrm{a}, \mathrm{b}}$, Jing Tian ${ }^{\mathrm{b}, *}$ Jeroen Meersmans $^{\mathrm{c}}$, Huajun Fang ${ }^{\mathrm{b}}$, Hao Yang ${ }^{\mathrm{b}}$, Yilai Lou ${ }^{\mathrm{d}, *}$ \\ Zhongfang Li ${ }^{\mathrm{e}}$, Kailou Liu ${ }^{\mathrm{e}}$, Yi Zhou ${ }^{\mathrm{a}}$, Evgenia Blagodatskaya, ${ }^{\mathrm{f}, \mathrm{g}}$, Yakov Kuzyakov, ${ }^{\mathrm{g}, \mathrm{h}}$ \\ a College of Geographical Science, Shanxi Normal University, Linfen 041000, China \\ $b$ Key Laboratory of Ecosystem Network Observation and Modeling, Institute of Geographic Sciences and Natural \\ Resources Research, Chinese Academy of Sciences (CAS), \\ ${ }^{c}$ School of Water, Energy and Environment, Cranfield University, Bedford MK43 OAL, UK \\ d Institute of Environment and Sustainable Development in Agriculture, Chinese Academy of Agricultural Sciences, \\ Beijing 100081, China \\ e National Engineering and Technology Research Center for Red Soil Improvement, Jiangxi Institute of Red Soil, \\ Nanchang 331717, China \\ fInstitute of Physicochemical and Biological Problems in Soil Science, Pushchino 142290, Russia \\ $g$ Department of Soil Science of Temperate Ecosystems, University of Göttingen, Göttingen 37077, Germany \\ h Department of Agricultural Soil Science, University of Göttingen, Göttingen 37077, Germany \\ *Corresponding authors: \\ Jing Tian, Phone: +86-10-64889808, Fax: +86-10-64868962, E-mail: tianj@igsnrr.ac.cn
}

\begin{abstract}
$\underline{\text { Abstract }}$
Soil organic matter (SOM) and its fractions play key roles in optimizing crop yield and improving soil quality. However, how functional SOM fractions responded to long-term fertilization and their relative importance for $\mathrm{C}$ sequestration were less addressed. In this study, we determined the effects of long-term fertilization on six functional SOM fractions (unprotected, physically protected, physico-biochemically protected, physico-chemi-cally protected, chemically protected, and biochemically protected) based on two long-term fertilization experiments carried out in South China. The unprotected coarse particulate organic matter (cPOM), the biochemically and chemically protected silt-sized fractions $(\mathrm{NH}-\mathrm{dSilt}$ and $\mathrm{H}-\mathrm{dSilt})$ were the primary $\mathrm{C}$ storage fractions under long-term fertilization, accounting for $23.6-46.2 \%, 15.7-19.4 \%$, and $14.4-17.4 \%$ of the total soil organic carbon (SOC) content in upland soil and 19.5-29.3\%, 9.9-15.5\%, and $14.2-17.2 \%$ of the total SOC content in paddy soil, respectively. Compared with the control treatment $(\mathrm{CK})$ in upland soil, the application of manure combined with mineral NPK (NPKM) resulted in an increase in the SOC content in the cPOM, pure physically protected fraction (iPOM), the physico-chemically protected $(\mathrm{H}-\mu \mathrm{Silt})$, and the chemically protected (H-dSilt) fraction by $233 \%, 166 \%, 124 \%$, and $58 \%$, respectively. Besides, the SOC increase in upland soil ex- pressed as SOC content per unit of total SOC for iPOM, H- $\mu$ Silt, cPOM and H-dSilt were the highest and as large as $283 \%, 248 \%, 194 \%$, and $105 \%$ respectively. In paddy soil, the highest increase per unit of total SOC was H-dSilt (190\%), followed by H-dClay (156\%) and H- $\mu$ Silt (155\%). These results suggested that the upland soil could stabilize more $C$ through the pure physical, whereas the chemical protection mechanism played a more important role in paddy soil. Chemical protection mechanism within the microaggregates played important roles in sequestrating $\mathrm{C}$ in both upland and paddy soils. Overall, the different responses of functional SOM fractions to long-term fertilization indicate different mechanisms for SOM cycling in terms of C sequestration under upland and paddy systems.
\end{abstract}

$\underline{\text { Keywords }}$

Long-term fertilization, Soil organic matter fraction, Physical and chemical fractionation Protection mechanism 


\section{$\underline{1 . \text { Introduction }}$}

Soil organic matter (SOM) is a key attribute for soil quality (Gregorich et al., 1994) and plays an important role in improving agricultural productivity (Smith et al., 2013). Furthermore, agricultural soils have the potential to mitigate global climate warming through $\mathrm{C}$ sequestration, counteracting increasing atmospheric CO2 concentrations (Lal, 2004). Therefore, there is a great need to better understand the mechanisms of maintaining high SOM levels and to seek the optimal management practices to enhance $\mathrm{C}$ stock in agricultural soils.

The effects of long-term fertilization (mineral or manure) on the soil organic carbon (SOC) content have been extensively investigated. Previous studies have reported positive (Purakayastha et al., 2008; Gong et al., 2009) or no effects (Yang et al., 2007; Hai et al., 2010; Lou et al., 2011) of long-term mineral fertilization on SOC content. In addition, a number of studies showed that the SOC content tends to respond positively to manure amendments (Wang et al., 2015; Blanchet et al., 2016); however this is not always the case and the drivers behind the associated potential C storage still remains not clearly understood (Meersmans et al., 2012).

SOM is generally considered to be composed of several functional fractions differing in their intrinsic degradability and in factors controlling decomposition rates (Stevenson, 1994; von Lützow et al., 2007; Li et al., 2017; Tian et al., 2017). Given the strong heterogeneity of SOM, the labile SOM fractions are characterized by their rapid turnover and considered as more sensitive indicators of the effects of management practices as compared to total SOM (Haynes, 2005; von Lützow et al., 2007; He et al., 2015). According to stabilization mechanisms, four fractions are separated from the bulk SOM: the biochemically protected, chemically protected, physically protected, and unprotected fractions (Six et al., 2002). The unprotected fraction, which is not occluded within microaggregates, is labile and is an important nutrient source (Six et al., 2002). SOM is physically protected from decomposition through the formation of microaggregates, chemically protected by mineral (silt and clay) particles, and biochemically protected through the formation of recalcitrant SOM compounds (Six et al., 2002). Manure and mineral fertilization increased the SOC content within the free POM, occluded POM, and the OM associated with minerals (Sleutel et al., 2006). Based on a 35-year field experiment, Tian et al. (2017) showed that the physical, chemical, and biochemical protection mechanisms are important in maintaining high SOC levels after the addition of manure, but the relative importance of SOM stabilization mechanisms for $\mathrm{C}$ sequestration related to long-term fertilization remains unclear.

The changing trend of sequestered $\mathrm{C}$ varies with the increasing $\mathrm{C}$ input under long-term fertilization conditions. A linear relationship between $\mathrm{C}$ sequestration and $\mathrm{C}$ input in the soil has been reported in previous long-term fertilization field experiments (Sun et al., 2013; Fan et al., 2014; Wang et al., 2015). A few long-term agroecosystem experiments showed that the SOC stock exhibited little or no change with the varying C input (Stewart et al., 2007), indicating that there is a maximum capacity of $\mathrm{C}$ sequestration in the soil, known as soil $\mathrm{C}$ saturation (Six et al., 2002; Stewart et al., 2007). However, only a limited number of studies have assessed the response of differential functional SOM fractions to $\mathrm{C}$ input under long-term fertilization conditions.

We hypothesized that (1) long-term fertilization will affect the functional SOM fractions, thus will influence the relative importance of different protection mechanisms in controlling $\mathrm{C}$ sequestration; and (2) the functional SOM fractions vary with the increasing $\mathrm{C}$ input under 
different fertilization practices. To test our hypotheses, we investigated the effects of long-term manure and mineral fertilization on various functional SOM fractions based on two long-term field experiments in upland and paddy soils, and quantified the response of functional SOM fractions to the $\mathrm{C}$ input under long-term fertilization conditions.

\section{Materials and methods}

\subsection{Study sites}

The two experimental sites (adjacent upland and paddy field) and located at the Institute of Red Soil, Jiangxi Province, China $\left(28^{\circ} 21^{\prime} \mathrm{N}, 116^{\circ} 10^{\prime} \mathrm{E}\right)$. This region is characterized by a subtropical climate with a mean annual temperature of $18.1^{\circ} \mathrm{C}$ and a mean annual precipitation of $1537 \mathrm{~mm}$. In the upland field, an early maize (Zea mays L.) - late maize - winter fallow rotation experiment has been conducted since 1986, whereas in the paddy field, an early rice (Oryza sativa L.) - late rice - winter fallow rotation experiment has been conducted since 1981. The upland soil had no irrigation measure and that for paddy soil was furrow irrigation. The upland and paddy soils are classified as red soil according to the Chinese soil classification system and developed from quaternary red clay parental materials. At the beginning of field experiments, the basic soil characteristics of plough horizon were $9.39 \mathrm{~g} \mathrm{~kg}-1 \mathrm{SOC}, 0.98 \mathrm{~g}$ $\mathrm{kg}-1$ total $\mathrm{N}, 60.3 \mathrm{mg} \mathrm{kg}-1$ available $\mathrm{N}$, and $\mathrm{pH} 6.0$ for the upland field, and were $16.3 \mathrm{~g} \mathrm{~kg}-$ $1 \mathrm{SOC}, 1.49 \mathrm{~g} \mathrm{~kg}-1$ total $\mathrm{N}, 144 \mathrm{mg} \mathrm{kg}-1$ available $\mathrm{N}$, and $\mathrm{pH} 6.9$ for the paddy field. All aboveground crop residues were removed from the field following harvest.

\subsection{Experimental design}

Both experiments were carried out in a randomized complete block design with three replicates per treatment. Each plot was $22.2 \mathrm{~m} 2$ in size in the upland field and $46.7 \mathrm{~m} 2$ in the paddy field. Four treatments were selected for this study, including: (1) control (CK, no fertilizer application); (2) N fertilizer application (N); (3) N, P, and K fertilizer application (NPK); and (4) combined N, P, and K fertilizer and manure application (NPKM). In both field experiments, urea, calcium-magnesium phosphate, and potassium chloride were used as $\mathrm{N}, \mathrm{P}$, and $\mathrm{K}$ fertilizers, respectively. The pig manure at a dose of $1500 \mathrm{~kg}$ ha- 1 (fresh weight) was applied for upland soil in each season. Manures for paddy soil were Chinese milkvetch (Astragalus sinicus) in the early rice season and pig manure in the late rice season and both of them were applied at $2250 \mathrm{~kg} \mathrm{ha}-1$ (fresh weight) in each season. The water contents for pig manure and Chinese milkvetch were $85.5 \%$ and $70.6 \%$ respectively. The dry matter of pig manure contained $340 \mathrm{~g} \mathrm{~kg}-1 \mathrm{C}, 6.0 \mathrm{~g} \mathrm{~kg}-1$ total $\mathrm{N}, 4.5 \mathrm{~g} \mathrm{~kg}-1$ total $\mathrm{P}$ and $5.0 \mathrm{~g} \mathrm{~kg}-1$ total $\mathrm{K}$, and that of Chinese milkvetch contained $467 \mathrm{~g} \mathrm{~kg}-1 \mathrm{C}, 4.0 \mathrm{~g} \mathrm{~kg}-1$ total N, $1.1 \mathrm{~g} \mathrm{~kg}-1$ total $\mathrm{P}$ and $3.5 \mathrm{~g} \mathrm{~kg}-1$ total $\mathrm{K}$.

In upland soil, the fertilizer rates were $60 \mathrm{~kg} \mathrm{~N}$ ha- 1, $30 \mathrm{~kg} \mathrm{P} 2 \mathrm{O} 5 \mathrm{ha}-1$, and $60 \mathrm{~kg} \mathrm{~K} 2 \mathrm{O}$ ha1 in each season. The $\mathrm{P}$ and $\mathrm{K}$ fertilizers and the pig manure were applied before maize seeding. The $\mathrm{N}$ fertilizer was applied $70 \%$ as basal fertilizer and $30 \%$ as topdressing fertilizer. While in paddy soil, the fertilizer rates were $90 \mathrm{~kg} \mathrm{~N}$ ha- 1, $45 \mathrm{~kg} \mathrm{P} 2 \mathrm{O} 5 \mathrm{ha}-1$, and $75 \mathrm{~kg} \mathrm{~K} 2 \mathrm{O}$ ha- 1 for each rice season. $\mathrm{P}$ and organic fertilizers were applied prior to rice seedling transplantation. Both $\mathrm{N}$ and $\mathrm{K}$ fertilizers were applied as topdressing fertilizers. The $\mathrm{N}$ fertilizer was divided into two parts and applied twice, whereas the $\mathrm{K}$ fertilizer was applied once.

\subsection{Soil sampling and analysis}


All soil samples were collected from the 0-20 cm deep layer in May 2015. In each plot, eight cores were randomly collected and pooled together as one composite sample. Subsequently, the composite samples were air-dried at room temperature and passed through a 2-mm sieve for further analysis. The C contents were measured by a Vario EL III Elemental Analyzer (Elementar, Germany).

\subsection{Soil SOM fractionation}

Functional SOM fractions were separated using a combined physical, chemical, and density fractionation method as described by Stewart et al. (2008, 2009) (Fig. 1). In the first step, three size fractions were obtained using physical fractionation and partial dispersion. They consisted of $>250 \mu \mathrm{m}$ coarse unprotected particulate organic matter (cPOM), 53-250 $\mu \mathrm{m}$ microaggregate fraction ( $\mu \mathrm{agg}$ ), and $<53 \mu \mathrm{m}$ easily dispersed silt and clay (dSilt and dClay). All the obtained fractions were oven-dried at $60{ }^{\circ} \mathrm{C}$ and weighed.

Fig. 1

Download high-res image (499KB)Download full-size image

Fig. 1. Soil fractionation scheme for isolating six $\mathrm{C}$ fractions: unprotected (cPOM + PPOM), physically protected (iPOM), physico-biochemically protected $(\mathrm{NH}-\mu \mathrm{Silt}+\mathrm{NH}-\mu \mathrm{Clay})$, physico-chemically protected $(\mathrm{H}-\mu \mathrm{Silt}+\mathrm{H}-\mu \mathrm{Clay})$, chemically protected (H-dSilt $+\mathrm{H}-\mathrm{dClay})$, and biochemically protected fractions (NH-dSilt + NH-dClay) (Stewart et al., 2008, 2009).

cPOM, coarse unprotected particulate organic matter; $\mu$ agg, microaggregate fraction; fPOM, fine unprotected POM; iPOM, microaggregate-protected POM; NH- $\mu$ Silt, nonhydrolyzable microaggregate-derived silt-sized fraction; $\mathrm{NH}-\mu \mathrm{Clay}$, nonhydrolyzable microaggregatederived clay-sized fraction; $\mathrm{H}-\mu$ Silt, hydrolyzable microaggregate-derived silt-sized fraction; $\mathrm{H}-\mu$ Clay, hydrolyzable microaggregate-derived clay-sized fraction; H-dSilt, hydrolyzable easily dispersed silt-sized fraction; H-dClay, hydrolyzable easily dispersed clay-sized fraction; NH-dSilt, nonhydrolyzable easily dispersed silt-sized fraction; NH-dClay, nonhydrolyzable easily dispersed clay-sized fraction.

In the second step, the microaggregate fraction isolated in the first step was further fractionated. Density flotation was used to isolate the fine unprotected POM fraction (fPOM) with $1.85 \mathrm{~g}$ $\mathrm{cm}-3$ sodium polytungstate. After fPOM was removed, dispersion was conducted for the heavy fraction to separate the $>53-\mu \mathrm{m}$ microaggregate-protected POM fraction (iPOM) and the microaggregate-derived silt- and clay-sized fractions ( $\mu$ Silt and $\mu \mathrm{Clay}$ ).

The third step was acid hydrolysis of the silt- and clay-sized fractions (dSilt, dClay, $\mu$ Silt, and $\mu$ Clay) isolated in the first two steps, as described by Plante et al. (2006). The process of acid hydrolysis included fluxing at $95^{\circ} \mathrm{C}$ for $16 \mathrm{~h}$ in $6 \mathrm{~mol} \mathrm{~L}-1 \mathrm{HCl}$ after which the suspension was filtered and washed using deionized water. All residues were oven-dried at $60{ }^{\circ} \mathrm{C}$ and weighed. The portions obtained from this step were the non-hydrolyzable fractions (NH-dSilt, $\mathrm{NH}-\mathrm{dClay}, \mathrm{NH}-\mu \mathrm{Silt}$, and $\mathrm{NH}-\mu \mathrm{Clay})$. Furthermore, the hydrolyzable fractions (H-dSilt, HdClay, $\mathrm{H}-\mu \mathrm{Silt}$, and $\mathrm{H}-\mu \mathrm{Clay}$ ) were determined by the difference between the whole fractions and the non-hydrolyzable fractions.

According to the fractionation scheme that is based on the assumed link between the isolated fractions and the protection mechanisms (Stewart et al., 2008), (i) the unprotected pool corresponds to cPOM and fPOM, (ii) the pure physically protected pool is iPOM, (iii) the physico-biochemically protected pool consists of non-hydrolyzable silt-and clay-sized 
fractions (NH- $\mu$ Silt and $\mathrm{NH}-\mu \mathrm{Clay})$ derived from the microaggregates, (iv) the physicochemically protected pool consists of hydrolyzable silt-and clay-sized fractions $(\mathrm{H}-\mu \mathrm{Silt}$ and $\mathrm{H}-\mu$ Clay) derived from the microaggregates, (v) the chemically protected pool is the hydrolyzable portion of the silt- and clay-sized fractions (H-dSilt and H-dClay), and (vi) the biochemically protected pool consists of the non-hydrolyzable portion remaining in the siltand clay-sized fractions after acid hydrolysis (NH-dSilt and NH-dClay).

\subsection{Statistical analysis}

The different SOM fractions and SOC content within them were analyzed using one-way analysis of variance (ANOVA) with SAS SystemV8 (SAS Inc., Cary, NC, USA). Differences were considered significant at $\mathrm{P}<0.05$, and a post-hoc least significant difference (LSD) test was carried out to compare differences among treatments.

The total SOC was used as a proxy for the $\mathrm{C}$ input to assess the effect of increased $\mathrm{C}$ input on SOC accumulation of functional SOM fractions among treatments as described by Stewart et al. (2008). Linear and logarithmic models were applied to evaluate the relationship between the SOC content in various fractions and the total SOC content, and the best-fit model was selected in terms of R2 value.

\section{$\underline{\text { 3. Results }}$}

\subsection{Distribution of functional SOM fractions}

Proportions of cPOM and fPOM fractions were higher under NPKM than under CK, in both upland and paddy soils $(\mathrm{P}<0.05$; Table 1$)$. The proportion of $\mathrm{cPOM}$ under $\mathrm{N}$ and the proportion of fPOM under NPK were higher than the respective values under CK, in both upland and paddy soils $(\mathrm{P}<0.05$; Table 1$)$. In paddy soil, the proportion of iPOM under NPKM was higher (by $123.5 \%)$ than that under $\mathrm{CK}(\mathrm{P}<0.05$; Table 1$)$. In comparison with $\mathrm{CK}$, balanced NPK fertilization increased the proportion of $\mathrm{iPOM}$ in upland soil, while unbalanced mineral fertilization $(\mathrm{N})$ decreased the amount of iPOM $(\mathrm{P}<0.05$; Table 1). In upland soil, the proportions of $\mathrm{NH}-\mu$ Silt and $\mathrm{NH}-\mu$ Clay were the highest under NPK $(\mathrm{P}<0.05$; Table 1$)$, whereas no significant differences were detected in the proportions of $\mathrm{NH}-\mu$ Silt or $\mathrm{NH}-\mu \mathrm{Clay}$ across the treatments in paddy soil. The proportions of H-dClay and NH-dClay under NPK were higher than those under $\mathrm{CK}$ in upland soil $(\mathrm{P}<0.05$; Table 1$)$. The proportions of $\mathrm{H}-\mathrm{dSilt}$, $\mathrm{H}$-dClay, NH-dSilt, and NH-dClay were lower under $\mathrm{N}$ than under $\mathrm{CK}$ in upland soil, whereas the proportion of $\mathrm{NH}$-dClay under mineral or combined with manure application was lower (by 9.7-18.6\%) than that under $\mathrm{CK}$ in paddy soil $(\mathrm{P}<0.05$; Table 1$)$.

\subsection{SOC content in functional SOM fractions}

The SOC content in cPOM, fPOM, and IPOM was the highest in NPKM under both upland and paddy soils $(\mathrm{P}<0.05$; Fig. $2 \mathrm{a}, \mathrm{b})$. The $\mathrm{SOC}$ content in $\mathrm{cPOM}$ was higher under sole $\mathrm{N}$ than under CK, by $70.3 \%$ and $34.2 \%$ in upland and paddy soils, respectively $(\mathrm{P}<0.05$; Fig. $2 \mathrm{a})$. The SOC content in iPOM was higher under balanced NPK than under N, by $132.7 \%$ and $39.1 \%$ in upland and paddy soils, respectively $(\mathrm{P}<0.05$; Fig. $2 \mathrm{~b})$. When compared to the increases in SOC contents in unprotected and pure physically protected fractions (cPOM, fPOM and iPOM), the increases in SOC contents observed in the physico-chemically, physicobiochemically, chemically and biochemically protected fractions were generally much smaller, both in absolute and relative terms (Fig. 2). As compared with CK treatment, the NPKM led to 
higher SOC contents in physico-chemically protected and physico-biochemically fractions $(\mathrm{H}-$ $\mu$ Silt, H- $\mu$ Clay, NH- $\mu$ Silt, and NH- $\mu$ Clay) in upland soil ( $\mathrm{P}<0.05$; Fig. $2 \mathrm{c}, \mathrm{d})$. On contrary, the NPKM treatment only increased the $\mathrm{H}-\mu$ Silt and $\mathrm{NH}-\mu$ Silt fractions in paddy soil $(\mathrm{P}<0.05$; Fig. 2c, d). In upland soil, the SOC content in H-dSilt and NH-dSilt was higher under NPKM than under $\mathrm{CK}(\mathrm{P}<0.05)$, whereas no significant differences were identified in $\mathrm{H}$-dSilt and $\mathrm{H}$ dClay in paddy soil among treatments (Fig. 2e, f).

\subsection{The relationships between SOC content in functional SOM fractions and total SOC}

Significant linear relationships between the SOC content in cPOM, iPOM, H- $\mu$ Silt, H-dSilt, and NH-dSilt with the total SOC were observed in upland soil $(\mathrm{P}<0.01$; Fig. 3a, b, c, e, f). Additionally, the increase in the SOC content per unit of total SOC (i.e., the slope of the linear regression equation) was $194 \%$ in cPOM, $283 \%$ in iPOM, $248 \%$ in $\mathrm{H}-\mu \mathrm{Silt}, 105 \%$ in $\mathrm{H}$-dSilt, and $17 \%$ in NH-dSilt. In upland soil, the SOC content in $\mathrm{H}-\mu \mathrm{Clay}, \mathrm{NH}-\mu \mathrm{Silt}, \mathrm{NH}-\mu \mathrm{Clay}$, and $\mathrm{H}$-dClay showed a significant logarithmic relationship with the total SOC $(\mathrm{P}<0.01$; Fig. $3 \mathrm{c}$, $\mathrm{d}$, e). The SOC content in POM and NH-dClay declined with increasing total SOC, though it was not significant statistically (Fig. 3a, f).

\section{Fig. 3}

Download high-res image (864KB)Download full-size image

Fig. 3. Relationship between soil organic carbon (SOC) content within functional soil organic matter (SOM) fractions and total SOC under long-term fertilization in upland and paddy soils.

The subscript letters $\mathrm{u}$ in legends refers to the fractions in upland soil and $\mathrm{p}$ refers to the fractions in paddy soil.

The SOC content was linearly related to the total SOC in cPOM, H- $\mu$ Silt, NH- $\mu$ Silt, NH- $\mu$ Clay, $\mathrm{H}-\mathrm{dSilt}$ and $\mathrm{H}$-dClay in paddy soil $(\mathrm{P}<0.01$; Fig. 3a, c, d, e). The increase in the SOC content per unit of total SOC was $81 \%$ in cPOM, $155 \% \mathrm{H}-\mu$ Silt, $42 \%$ in NH- $\mu$ Silt, $55 \%$ in NH- $\mu$ Clay, $190 \% \mathrm{H}-\mathrm{dSilt}$ and $156 \%$ in H-dClay, respectively. No obvious increasing trend was found in SOC content of fPOM, iPOM, H- $\mu$ Clay, and NH-dSilt with increased total SOC (Fig. 3a, b, c, f). The SOC content of NH-dClay declined with increasing total SOC, though it was not significant statistically (Fig. 3f).

\section{$\underline{\text { 4. Discussion }}$}

\subsection{Effects of long-term fertilization on functional SOM fractions}

The combined mineral and manure application (NPKM) significantly increased not only the proportions of unprotected cPOM and PPOM fractions but also their SOC content in both upland and paddy soils (Table 1, Fig. 2a). Similar results were reported by Tian et al. (2017), who found that manure addition increased SOC content in CPOM or fPOM, especially combined with mineral fertilizer. The unprotected fractions mainly consist of the plant-derived residues that are partially decomposed, but also comprise seeds and microbial debris (e.g., fungal hyphae and spores) (Six et al., 2002). The increase in unprotected fractions by the combined application of mineral and manure fertilizers might be the result of the direct effect of manure addition (Tian et al., 2017). Besides the direct effect of manure addition, the addition of manure or in combination with mineral fertilizers may result in better crop growth, such as larger root biomass (E et al., 2012) and higher crop yields (Tong et al., 2014), than that under a treatment lacking fertilizers. Consequently, the increased input of plant residues into the soil 
leads to a high bulk organic matter content as well as high SOC content in the unprotected fractions.

The NPKM treatment enhanced the SOC content in IPOM both in upland and paddy soils, which was consistent with the results obtained in previous field experiments (Sleutel et al., 2006; Huang et al., 2010; He et al., 2015; Tian et al., 2017). As SOM is a major binding agent of soil aggregates (Six et al., 2004), the input of manure may provide the binding materials for the formation of micro-aggregates, which could enhance the stabilization of SOC which has become physically protected within these newly formed micro-aggregates (Tisdall and Oades, 1982). Consequently, in our study, the increased SOC content in iPOM might be attributed to the increased soil microaggregation after manure amendments (Su et al., 2006; Tian et al., 2017), which could be beneficial to slow down the turnover rate of SOM and thus, contribute to C stabilization (Pulleman et al., 2003; Marriott and Wander, 2006; Hai et al., 2010). Indeed, this was confirmed by our study, we found that long-term NPKM fertilization increased the proportion of iPOM by $17.2 \%$ and $123.5 \%$ for upland and paddy soils compared with CK (Table 1), and led to the highest SOC content in iPOM in both upland and paddy soils (Fig. 2). The SOC content and the proportion of iPOM under NPK was significantly higher than under $\mathrm{N}$ (Table 1, Fig. 2b), indicating that the balanced application of $\mathrm{N}, \mathrm{P}$, and $\mathrm{K}$ fertilizers had a more positive effect on iPOM than the $\mathrm{N}$ fertilizer application in both field experiments. A large amount of available $\mathrm{N}$ was contained in the mineral fertilizer, which could facilitate the crop growth but likewise the microbial activity that might enhance the decomposition in intramicroaggregate POC (iPOC) (Liu et al., 2010). NPK might have a stronger stimulation effect on crop growth than on SOC decomposition, leading to a net accumulation of plant residues into the soil and increased SOC in iPOC (He et al., 2015). Previous studies indicate that stabilization of POM within microaggregates (i.e., iPOM in our study) is one of the major protection mechanisms (Zotarelli et al., 2007; Six and Paustian, 2014). Our study confirms these findings by showing that long-term balanced mineral fertilization and manure application were crucial for SOC sequestration.

The biochemically protected SOM fraction is a non-hydrolyzable fraction that is protected against decomposition by biochemical stabilization mechanisms due to its own complex chemical composition and depends on the residue quality or can be acquired by the condensation and complexation reactions related to the organic matter decomposition process in the soil over time (Six et al., 2002). The SOC content of NH-dSilt and NH-dClay in paddy soil significantly lowered, averaged by $18.4 \%$ and $28.8 \%$, respectively, after long-term fertilization than that under control (Fig. 2f), likely due to the reduced proportion of soil dry matter in the biochemical SOM fraction of the whole soil. In addition, the reduction in the proportions and SOC contents of NH-dSilt and NH-dClay suggests that fertilization might accelerate the decomposition of biochemically protected fractions in paddy soil, which was under anoxic conditions. A close relationship between the amount of $\mathrm{C}$ protected by silt and clay particles and the silt plus clay proportion in the fraction were observed in a previous study (Hassink, 1997). In the present study, the amounts of SOC in biochemically and chemically protected silt-sized fractions were greater than that in biochemically and chemically protected clay-sized fractions, revealing that silt and clay may have different susceptibility in response to hydrolyzation (Amelung et al., 1999; Kiem and Kogel-Knabner, 2003). The different carbohydrate concentrations may account for differences in the hydrolyzability of the two fractions (Stewart et al., 2008). The aggregate-associated mineral fractions (H- $\mu$ Silt, H- $\mu$ Clay, $\mathrm{NH}-\mu \mathrm{Silt}$, and $\mathrm{NH}-\mu \mathrm{Clay}$ ) were generally considered to be stable fractions that occluded within microaggregates or associated with silt and clay. Stewart et al. (2009) found that the response of un-aggregated silt and clay to $\mathrm{C}$ additions was faster than that of aggregate-mineral fractions. 
In the present study, we found that the SOC content in the physico-chemically and physicobiochemically protected fractions in both upland and paddy soils was enhanced by the combined addition of mineral and manure fertilizers, except for $\mathrm{NH}-\mu \mathrm{Clay}$ and $\mathrm{H}-\mu \mathrm{Clay}$ in paddy soil (Fig. 2c, d). In contrast, a pronounced increase was only observed in H-dSilt and NH-dSilt in upland soil (Fig. 2e, f), indicating that the aggregate-associated mineral fractions and the easily dispersed mineral fractions responded differently to long-term fertilization and that different protection mechanisms might be responsible for different responses of these fractions.

\subsection{Response of SOC content within functional SOM fractions to total SOC}

The SOC content of unprotected cPOM increased with the increasing total SOC in both upland and paddy soils, suggesting that the upland and paddy soils might still have a potential to sequester and stabilize more $\mathrm{C}$ in $\mathrm{cPOM}$ fraction under the present conditions. This result was in agreement with that reported in a previous study showing that the CPOM fractions fitted the linear model best (Stewart et al., 2008). However, we observed that SOC content of fPOM declined, but not significant, with increasing total SOC in upland soil (Fig. 3a), suggesting that a negative relationship existed between SOC content of fPOM and total SOC. Six et al. (2002) suggested that OC in light fraction (fPOM in our study) did not increase with the increasing C input at some sites. One possible explanation could be that the saturation behavior of the unprotected fraction depends on the balance between the $\mathrm{C}$ input and the specific decomposition rate of the fraction, whereas the different saturation behavior of the unprotected fraction might be due to various factors such as soil temperature, moisture, and substrate biodegradability (Stewart et al., 2008). Moreover, the negative relationships between the SOC content of fPOM and the total SOC may be attributed to the priming effects that SOC of this fraction have been consumed by the increased microbial activity after fertilization (Blagodatskaya and Kuzyakov, 2008).

The SOC content in IPOM had a positive linear relationship with the total SOC in upland soil (Fig. 3b), which was inconsistent with previous studies. Six et al. (2002) reported that the physical protection of POM has a limited capacity due to the content and type of clay available for POM protection in this fraction, and thus iPOM shows the maximum level of $\mathrm{C}$ stabilization. In addition, Kölbl and Kögel-Knabner (2004) showed a curvilinear relationship between the clay content and the occluded POC, indicating that the maximum amount of $\mathrm{C}$ is present in the physically protected POM fraction (Stewart et al., 2008). However, in the present study, no obvious increase in the SOC content of iPOM with the increasing total SOC was detected in paddy soil (Fig. 3b), revealing distinct management practices and environmentspecific SOM decomposition rates in upland and paddy soils. More precisely, SOM decomposition in paddy soil is markedly slow as a result of the anaerobic conditions due to the long-term water-logging (Sahrawat, 2004). Hence, the limited SOC mineralization capacity under these conditions may probably allow iPOM to approach an equilibrium level after longterm fertilization and probably reach the saturation level.

The higher SOC increase per unit of total SOC in H-dSilt, H-dClay and H- $\mu$ Silt in paddy soil and in $\mathrm{H}-\mu \mathrm{Silt}$ in upland soil (Fig. 3c, e), suggesting that physico-chemical and chemical protection mechanisms played important roles in stabilizing SOC in paddy soil and the upland soil could accumulate more $\mathrm{C}$ through the physico-chemical protection mechanism. The increase in $\mathrm{H}-\mu$ Silt might be due to the existence of free Fe-oxyhydrates that could enhance the physico-chemical protection of SOC in paddy soil (Zheng et al., 2012). In contrast, the SOC content in the H- $\mu$ Clay, $\mathrm{H}-\mathrm{dClay}$ and physico-biochemically protected fractions in upland soil 
had little increase with increasing total SOC, as well as the H- $\mu$ Clay and NH-dClay in paddy soil (Fig. 3c, d, e, f). The fact that the $\mathrm{C}$ saturation levels of these fractions seem to be approaching can be attributed to their slower $\mathrm{C}$ turnover rate compared with that in $\mathrm{CPOM}$ (Chung et al., 2008). These results were in agreement with a previous study showing that both linear and saturation model fitted physico-chemically and physico-biochemically protected fractions (Stewart et al., 2008). The SOC content of biochemically protected fractions in upland and paddy soils had no obvious further increase with increasing SOC, except that NH-dSilt in upland soil showed a significant positive linear relationship with the total SOC (Fig. 3f). Previous studies reported that more hemicellulose and cellulose and less lignin, tannin, and polyphenolic materials are present in rice residues compared with maize residues (Zhou et al., 2010; Yan et al., 2013). Therefore, the maize residues in upland soil are generally decomposed slower than rice residues in paddy soil (Wang et al., 2004), and consequently, the upland soil might have a greater capacity to stabilize more $\mathrm{C}$ through the biochemical protection mechanism in NH-dSilt. On the other hand, a broader range of $\mathrm{C}$ inputs might be needed to elicit C saturation behavior (Stewart et al., 2007). Besides, the SOC content in NH-dClay in upland and paddy soils decreased with the increasing total SOC indicated that priming effect might also occur in NH-dClay, although the changing trend was not significant statistically. However, owing to the inconsistent relationships between the SOC content stabilized by the various protection mechanisms and the total SOC in upland and paddy soils, further analysis for the functional SOM fractions of different soil types under long-term fertilization is necessary.

\section{Conclusions}

The SOC content in cPOM, iPOM, H- $\mu$ Silt and H-dSilt increased (by 58-233\%) under NPKM than under CK in upland soil and showed a relatively highest increase per unit of total SOC. However, in paddy soil, the highest increase in SOC per unit of total SOC was present in HdSilt, followed by H-dClay and $\mathrm{H}-\mu$ Silt. Thus, our results suggest that the upland soil could stabilize more $\mathrm{C}$ through the pure physical, whereas the chemical protection mechanism played a more important role in paddy soil. Chemical protection mechanism within the microaggregates played important roles in sequestrating $\mathrm{C}$ in both upland and paddy soils. In summary, the different responses of functional SOM fractions to long-term fertilization indicate different mechanisms for SOM cycling in terms of $\mathrm{C}$ sequestration under different management practices and land use types. Future studies are necessary to investigate the protection mechanisms and the $\mathrm{C}$ sequestration capacity related to long-term fertilization under different agro- and soil-type systems.

\section{$\underline{\text { Acknowledgements }}$}

This study was supported by the National Natural Science Foundation of China (Grant No. 31400460, 41571130041), the Major Program of the National Natural Science Foundation of China (Grant No. 31420103917), the Youth Innovation Research Team Project (LENOM2016Q0004) and S \& T Innovation Program of CAAS. We also thank the editor and two anonymous reviewers for their valuable comments that helped us to greatly improve the manuscript. 


\section{$\underline{\text { References }}$}

Amelung, W., Flach, K.W., Zech, W., 1999. Lignin in particle-size fractions of native grassland soils as influenced by climate. Soil Sci. Soc. Am. J. 63, 1222-1228.

Blagodatskaya, E., Kuzyakov, Y., 2008. Mechanisms of real and apparent priming effects and their dependence on soil microbial biomass and community structure: critical review. Biol. Fertil. Soils 45, 115-131.

Blanchet, G., Gavazov, K., Bragazza, L., Sinaj, S., 2016. Responses of soil properties and crop yields to different inorganic and organic amendments in a Swiss conventional farming system. Agric. Ecosyst. Environ. 230, 116-126.

Chung, H., Grove, J.H., Six, J., 2008. Indications for soil carbon saturation in a temperate agroecosystem. Soil Sci. Soc. Am. J. 72, 1132-1139.

E, S.Z., Li, X.G., Chen, Z.M., Li, X.H., Song, J.R., Guggenberger, G., 2012. Long-term fertilization and manuring effects on physically separated soil organic-matter pools under continuous wheat cropping at a rainfed semiarid site in China. J. Plant Nutr. Soil Sci. 175, 689697.

Fan, J.L., Ding, W.X., Xiang, J., Qin, S.W., Zhang, J.B., Ziadi, N., 2014. Carbon sequestration in an intensively cultivated sandy loam soil in the North China Plain as affected by compost and inorganic fertilizer application. Geoderma 230, 22-28.

Gong, W., Yan, X.Y., Wang, J.Y., Hu, T.X., Gong, Y.B., 2009. Long-term manuring and fertilization effects on soil organic carbon pools under a wheat-maize cropping system in North China Plain. Plant Soil 314, 67-76.

Gregorich, E.G., Carter, M.R., Angers, D.A., Monreal, C.M., Ellert, B.H., 1994. Towards a minimum data set to assess soil organic matter quality in agricultural soils. Can. J. Soil Sci. 74, 367-385.

Hai, L., Li, X.G., Li, F.M., Suo, D.R., Georg, G., 2010. Long-term fertilization and manuring effects on physically-separated soil organic matter pools under a wheat-wheat-maize cropping system in an arid region of China. Soil Biol. Biochem. 42, 253-259.

Hassink, J., 1997. The capacity of soils to preserve organic $\mathrm{C}$ and $\mathrm{N}$ by their association with clay and silt particles. Plant Soil 191, 77-87.

Haynes, R.J., 2005. Labile organic matter fractions as central components of the quality of agricultural soils: an overview. Adv. Agron. 85, 221-268.

He, Y.T., Zhang, W.J., Xu, M.G., Tong, X.G., Sun, F.X., Wang, J.Z., Huang, S.M., Zhu, P., He, X.H., 2015. Long-term combined chemical and manure fertilizations increase soil organic carbon and total nitrogen in aggregate fractions at three typical cropland soils in China. Sci. Total Environ. 532, 635-644. 
Huang, S., Peng, X.X., Huang, Q.R., Zhang, W.J., 2010. Soil aggregation and organic carbon fractions affected by long-term fertilization in a red soil of subtropical China. Geoderma 154, 364-369.

Kiem, R., Kogel-Knabner, I., 2003. Contribution of lignin and polysaccharides to the refractory carbon pool in C-depleted arable soils. Soil Biol. Biochem. 35, 101-118.

Kölbl, A., Kögel-Knabner, I., 2004. Content and composition of free and occluded particulate organic matter in a differently textured arable Cambisol as revealed by solid-state 13C NMR spectroscopy. J. Plant Nutr. Soil Sci. 167, 45-53.

Lal, R., 2004. Soil carbon sequestration impacts on global climate change and food security. Science 304, 1623-1627.

Li, X.G., Jia, B., Lv, J.T., Ma, Q.J., Kuzyakov, Y., Li, F.M., 2017. Nitrogen fertilization decreases the decomposition of soil organic matter and plant residues in planted soils. Soil Biol. Biochem. 112, 47-55.

Li, Z.P., Liu, M., Wu, X.C., Han, F.X., Zhang, T.L., 2010. Effects of long-term chemical fertilization and organic amendments on dynamics of soil organic $\mathrm{C}$ and total $\mathrm{N}$ in paddy soil derived from barren land in subtropical China. Soil Tillage Res. 106, 268-274.

Li, C., Cao, Z. Chang, J., Zhang, Y., Zhu, G., Zong, N., He, Y., Zhang, J. He, N. 2017. Elevational gradient affect functional fractions of soil organic carbon and aggregates stability in a Tibetan alpine meadow Catena, 156, 139-148.

Liu, H., Tong, X.G., Xu, Y.M., Ma, X.W., Wang, X.H., Zhang, W.J., Xu, M.G., 2010. Evolution characteristics of organic carbon fractions in grey desert soil under long-term fertilization. Plant Nutr. Fertil. Sci. 16, 794-800.

Lou, Y., Xu, M., Wang, W., Sun, X., Liang, C., 2011. Soil organic carbon fractions and management index after $20 \mathrm{yr}$ of manure and fertilizer application for greenhouse vegetables. Soil Use Manage. 27, 163-169.

von Lützow, M., Kögel-Knabner, I., Ekschmitt, K., Flessa, H., Guggenberger, G., Matzner, E., Marschner, B., 2007. SOM fractionation methods: relevance to functional pools and to stabilization mechanisms. Soil Biol. Biochem. 39, 2183-2207.

Marriott, E.E., Wander, M., 2006. Qualitative and quantitative differences in particulate organic matter fractions in organic and conventional farming systems. Soil Biol. Biochem. 38, $1527-1536$.

Meersmans, J., Martin, M.P., De Ridder, F., Lacarce, E., Wetterlind, J., De Baets, S., Le Bas, C., Louis, B.P., Orton, T.G., Bispo, A., Arrouays, D. 2012. A novel soil organic C model using climate, soil type and management data at the national scale in France. Agron. Sustain. Dev. $32,873-888$.

Plante, A.F., Conant, R.T., Stewart, C.E., Paustian, K., Six, J., 2006. Impact of soil texture on the distribution of soil organic matter in physical and chemical fractions. Soil Sci. Soc. Am. J. 70, 287-296. 
Pulleman, M., Jongmans, A., Marinissen, J., Bouma, J., 2003. Effects of organic versus conventional arable farming on soil structure and organic matter dynamics in a marine loam in the Netherlands. Soil Use Manage. 19, 157-165.

Purakayastha, T.J., Rudrappa, L., Singh, D., Swarup, A., Bhadraray, S., 2008. Long-term impact of fertilizers on soil organic carbon pools and sequestration rates in maize-wheatcowpea cropping system. Geoderma 144, 370-378.

Sahrawat, K.L., 2004. Organic matter accumulation in submerged soils. Adv. Agron. 81, 169201.

Six, J., Bossuyt, H., Degryze, S., Denef, K., 2004. A history of research on the link between (micro) aggregates, soil biota, and soil organic matter dynamics. Soil Tillage Res. 79, 7-31.

Six, J., Conant, R.T., Paul, E.A., Paustian, K., 2002. Stabilization mechanisms of soil organic matter: Implications for C-saturation of soils. Plant Soil 241, 155-176.

Six, J., Paustian, K., 2014. Aggregate-associated soil organic matter as an ecosystem property and a measurement tool. Soil Biol. Biochem. 68, A4-A9.

Sleutel S., De Neve S., Németh T., Tóth T., Hofman G., 2006. Effect of manure and fertilizer application on the distribution of organic carbon in different soil fractions in long-term field experiments. Eur. J. Agron. 25, 280-288.

Smith, P., Ashmore, M.R., Black, H.I., Burgess, P.J., Evans, C.D., Quine, T.A., Thomson, A.M., Hicks, K., Orr, H.G., 2013. REVIEW: the role of ecosystems and their management in regulating climate, and soil, water and air quality. J. Appl. Ecol. 50, 812-829.

Stevenson, F.J., 1994. Humus chemistry: genesis, composition, reactions. John Wiley and Sons, New York.

Stewart, C.E., Paustian, K., Conant, R.T., Plante, A.F., Six, J., 2007. Soil carbon saturation: concept, evidence and evaluation. Biogeochemistry 86, 19-31.

Stewart, C.E., Paustian, K., Conant, R.T., Plante, A.F., Six, J., 2009. Soil carbon saturation: Implications for measurable carbon pool dynamics in long-term incubations. Soil Biol. Biochem. 41, 357-366.

Stewart, C.E., Plante, A.F., Paustian, K., Conant, R.T., Six, J., 2008. Soil carbon saturation: Linking concept and measurable carbon pools. Soil Sci. Soc. Am. J. 72, 379-392.

Su, Y.Z., Wang, F., Suo, D.R., Zhang, Z.H., Du, M.W., 2006. Long-term effect of fertilizer and manure application on soil-carbon sequestration and soil fertility under the wheat-wheatmaize cropping system in northwest China. Nutr. Cycl. Agroecosyst. 75, 285-295.

Sun, Y.N., Huang, S., Yu, X.C., Zhang, W.J., 2013. Stability and saturation of soil organic carbon in rice fields: evidence from a long-term fertilization experiment in subtropical China. J. Soil Sediment. 13, 1327-1334. 
Tian, J., Lou, Y.L., Gao, Y., Fang, H.J., Liu, S.T., Xu, M.G., Blagodatskaya, E., Kuzyakov, Y., 2017. Response of soil organic matter fractions and composition of microbial community to long-term organic and mineralfertilization. Biol. Fertil. Soils, 53, 523-532.

Tisdall, J.M., Oades, J.M., 1982. Organic matter and water-stable aggregates in soils. Eur. J. Soil Sci. 33, 141-163.

Wang, W.J., Baldock, J.A., Dalal, R.C., Moody, P.W., 2004. Decomposition dynamics of plant materials in relation to nitrogen availability and biochemistry determined by NMR and wetchemical analysis. Soil Biol. Biochem. 36, 2045-2058.

Wang, Y.D., Hu, N., Xu, M.G., Li, Z.F., Lou, Y.L., Chen, Y., Wu, C.Y., Wang, Z.L., 2015. 23-year manure and fertilizer application increases soil organic carbon sequestration of a ricebarley cropping system. Biol. Fertil. Soils 51, 583-591.

Yan, X., Zhou, H., Zhu, Q.H., Wang, X.F., Zhang, Y.Z., Yu, X.C., Peng, X., 2013. Carbon sequestration efficiency in paddy soil and upland soil under long-term fertilization in southern China. Soil Tillage Res. 130, 42-51.

Yang, Z.H., Singh, B.R., Hansen, S., 2007. Aggregate associated carbon, nitrogen and sulfur and their ratios in long-term fertilized soils. Soil Tillage Res. 95, 161-171.

Zheng, J., Li, L., Pan, G., Zhang, X., Smith, P., Hussain, Q., 2012. Potential aerobic C mineralization of a red earth paddy soil and its temperature dependence under long-term fertilizer treatments. Soil Use Manage. 28, 185-193.

Zhou, P., Pan, G.X., Spaccini, R., Piccolo, A., 2010. Molecular changes in particulate organic matter (POM) in a typical Chinese paddy soil under different long-term fertilizer treatments. Eur. J. Soil Sci. 61, 231-242.

Zotarelli, L., Alves, B.J.R., Urquiaga, S., Boddey, R.M., Six, J., 2007. Impact of tillage and crop rotation on light fraction and intra-aggregate soil organic matter in two Oxisols. Soil Tillage Res. 95, 196-206. 


\begin{tabular}{|c|c|c|c|c|c|c|c|c|c|c|c|c|}
\hline \multirow{2}{*}{ Sites } & \multirow{2}{*}{ Treatments } & \multicolumn{2}{|c|}{ Unprotected } & \multirow{2}{*}{$\begin{array}{c}\text { Physically protected } \\
\text { iPOM } \\
\end{array}$} & \multicolumn{2}{|c|}{ Physico-biochemically protected } & \multicolumn{2}{|c|}{ Physico-chemically protected } & \multicolumn{2}{|c|}{ Chemically protected } & \multicolumn{2}{|c|}{ Biochemically protected } \\
\hline & & cPOM & fPOM & & $\mathrm{NH}-\mu \mathrm{Silt}$ & $\mathrm{NH}-\mu \mathrm{Clay}$ & $\mathrm{H}-\mu \mathrm{Silt}$ & H- $\mu$ Clay & H-dSilt & H-dClay & NH-dSilt & NH-dClay \\
\hline \multirow{4}{*}{ Upland soil } & CK & $25.4 \mathrm{~b}$ & $0.10 \mathrm{c}$ & $3.90 \mathrm{~b}$ & $12.1 \mathrm{~b}$ & $2.67 \mathrm{~b}$ & $2.82 \mathrm{a}$ & $3.56 \mathrm{ab}$ & $11.0 \mathrm{ab}$ & $0.72 b$ & $36.3 b$ & $0.65 b$ \\
\hline & $\mathrm{N}$ & $31.3 \mathrm{a}$ & $0.13 \mathrm{c}$ & $2.54 \mathrm{c}$ & $11.5 b$ & $2.91 \mathrm{ab}$ & $2.27 \mathrm{~b}$ & $3.62 \mathrm{ab}$ & $9.53 \mathrm{c}$ & $0.51 \mathrm{c}$ & $31.0 \mathrm{~d}$ & $0.39 \mathrm{c}$ \\
\hline & NPK & $25.5 b$ & $0.21 \mathrm{~b}$ & $5.73 \mathrm{a}$ & $13.5 \mathrm{a}$ & $3.21 \mathrm{a}$ & $2.67 \mathrm{a}$ & $3.84 \mathrm{a}$ & $10.2 \mathrm{bc}$ & $0.93 \mathrm{a}$ & $34.4 \mathrm{c}$ & $0.85 \mathrm{a}$ \\
\hline & NPKM & $31.3 \mathrm{a}$ & $0.25 \mathrm{a}$ & $4.57 \mathrm{ab}$ & $11.7 \mathrm{~b}$ & $2.59 \mathrm{~b}$ & $2.50 \mathrm{ab}$ & $3.26 \mathrm{~b}$ & $11.7 \mathrm{a}$ & $0.74 \mathrm{~b}$ & $41.1 \mathrm{a}$ & $0.67 \mathrm{~b}$ \\
\hline \multirow{4}{*}{ Paddy soil } & CK & $17.5 \mathrm{c}$ & $0.16 \mathrm{c}$ & $2.79 b$ & $16.2 \mathrm{a}$ & $1.76 \mathrm{a}$ & $3.65 \mathrm{ab}$ & $2.05 \mathrm{a}$ & $7.93 a$ & $0.42 \mathrm{a}$ & $38.7 \mathrm{a}$ & $0.42 \mathrm{a}$ \\
\hline & $\mathrm{N}$ & $22.8 \mathrm{~b}$ & $0.17 \mathrm{c}$ & $3.31 \mathrm{~b}$ & $13.3 \mathrm{a}$ & $1.52 \mathrm{a}$ & $2.81 \mathrm{~b}$ & $1.91 \mathrm{a}$ & $8.38 \mathrm{a}$ & $0.37 \mathrm{a}$ & $36.0 \mathrm{~b}$ & $0.36 \mathrm{~b}$ \\
\hline & NPK & $17.7 \mathrm{c}$ & $0.22 \mathrm{~b}$ & $5.36 \mathrm{a}$ & $16.6 \mathrm{a}$ & $1.61 \mathrm{a}$ & $3.80 \mathrm{a}$ & $2.16 \mathrm{a}$ & $7.72 \mathrm{a}$ & $0.39 \mathrm{a}$ & $37.3 \mathrm{ab}$ & $0.34 b$ \\
\hline & NPKM & $27.9 \mathrm{a}$ & $0.29 \mathrm{a}$ & $6.24 \mathrm{a}$ & $16.6 \mathrm{a}$ & $1.72 \mathrm{a}$ & $3.86 \mathrm{a}$ & $2.36 \mathrm{a}$ & $6.79 \mathrm{a}$ & $0.37 \mathrm{a}$ & $32.94 \mathrm{c}$ & $0.38 \mathrm{~b}$ \\
\hline
\end{tabular}

Different lower-case letters indicate significant differences $(\mathrm{p}<0.05)$ among treatments within each site. $\mathrm{CK}$, control; N, N fertilizer application; NPK, N, P, and $\mathrm{K}$ fertilizer application; NPKM, combined N, P, and K fertilizer and manure application.

Table 1. Distribution of the functional soil organic matter (SOM) fractions (\%) under long-term fertilization in upland and paddy soils. 


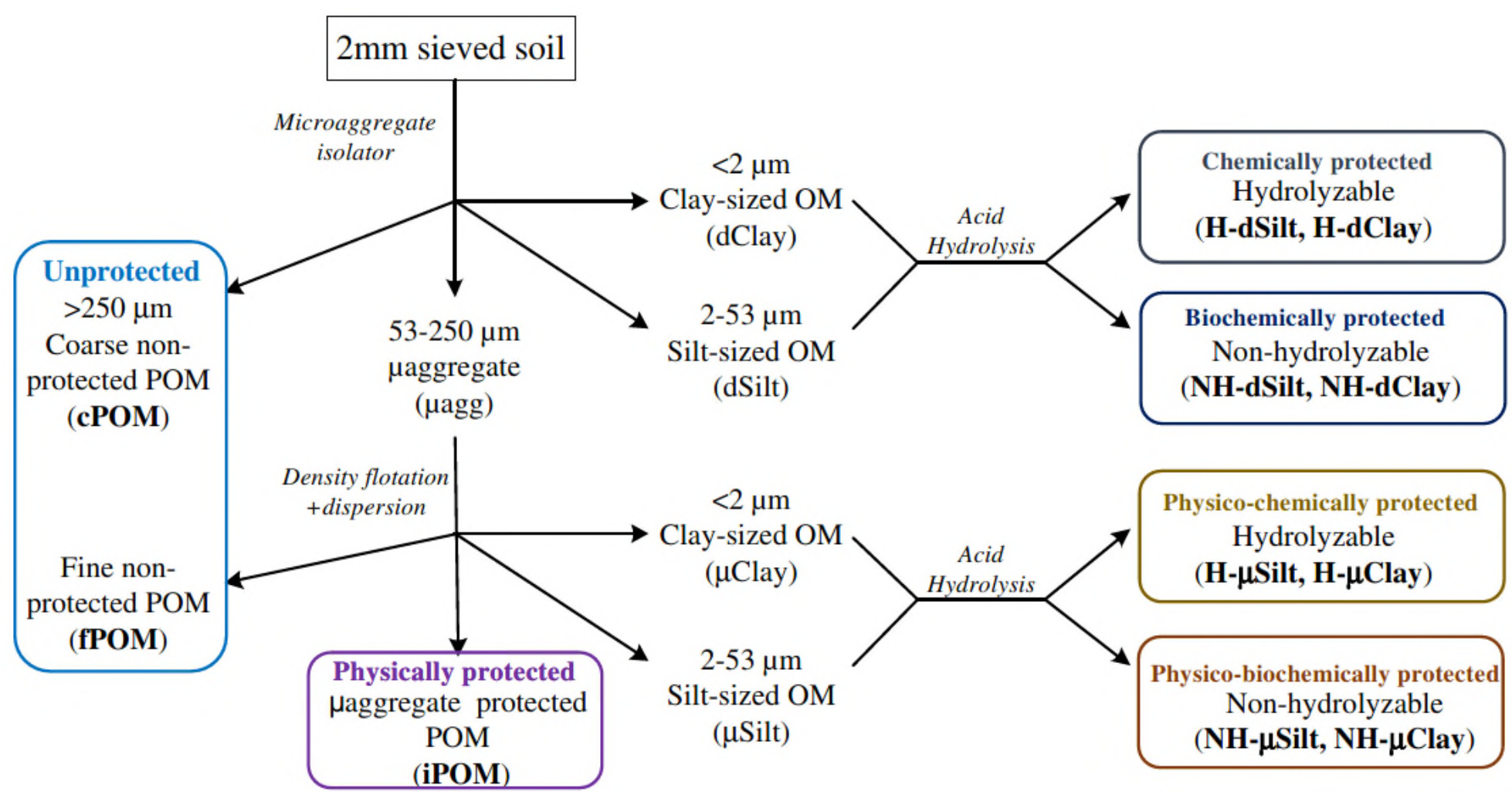

Fig. 1 Soil fractionation scheme for isolating six $\mathrm{C}$ fractions: unprotected (cPOM + fPOM), physically protected (iPOM), physico-biochemically protected (NH- $\mu \mathrm{Silt}+\mathrm{NH}-\mu \mathrm{Clay})$, physico-chemically protected $(\mathrm{H}-\mu \mathrm{Silt}+\mathrm{H}-\mu \mathrm{Clay})$, chemically protected $(\mathrm{H}-\mathrm{dSilt}+\mathrm{H}-\mathrm{dClay})$, and biochemically protected fractions (NH-dSilt + NH-dClay) (Stewart et al. 2008, 2009). cPOM, coarse unprotected particulate organic matter; $\mu$ agg, microaggregate fraction; fPOM, fine unprotected POM; iPOM, microaggregate-protected POM; NH- $\mu$ Silt, nonhydrolyzable microaggregate-derived silt-sized fraction; $\mathrm{NH}-\mu \mathrm{Clay}$, nonhydrolyzable microaggregate-derived clay-sized fraction; H- $\mu$ Silt, hydrolyzable microaggregate-derived silt-sized fraction; H- $\mu$ Clay, hydrolyzable microaggregate-derived clay-sized fraction; H-dSilt, hydrolyzable easily dispersed silt-sized fraction; H-dClay, hydrolyzable easily dispersed clay-sized fraction; NH-dSilt, nonhydrolyzable easily dispersed silt-sized fraction; NH-dClay, nonhydrolyzable easily dispersed clay-sized fraction. 

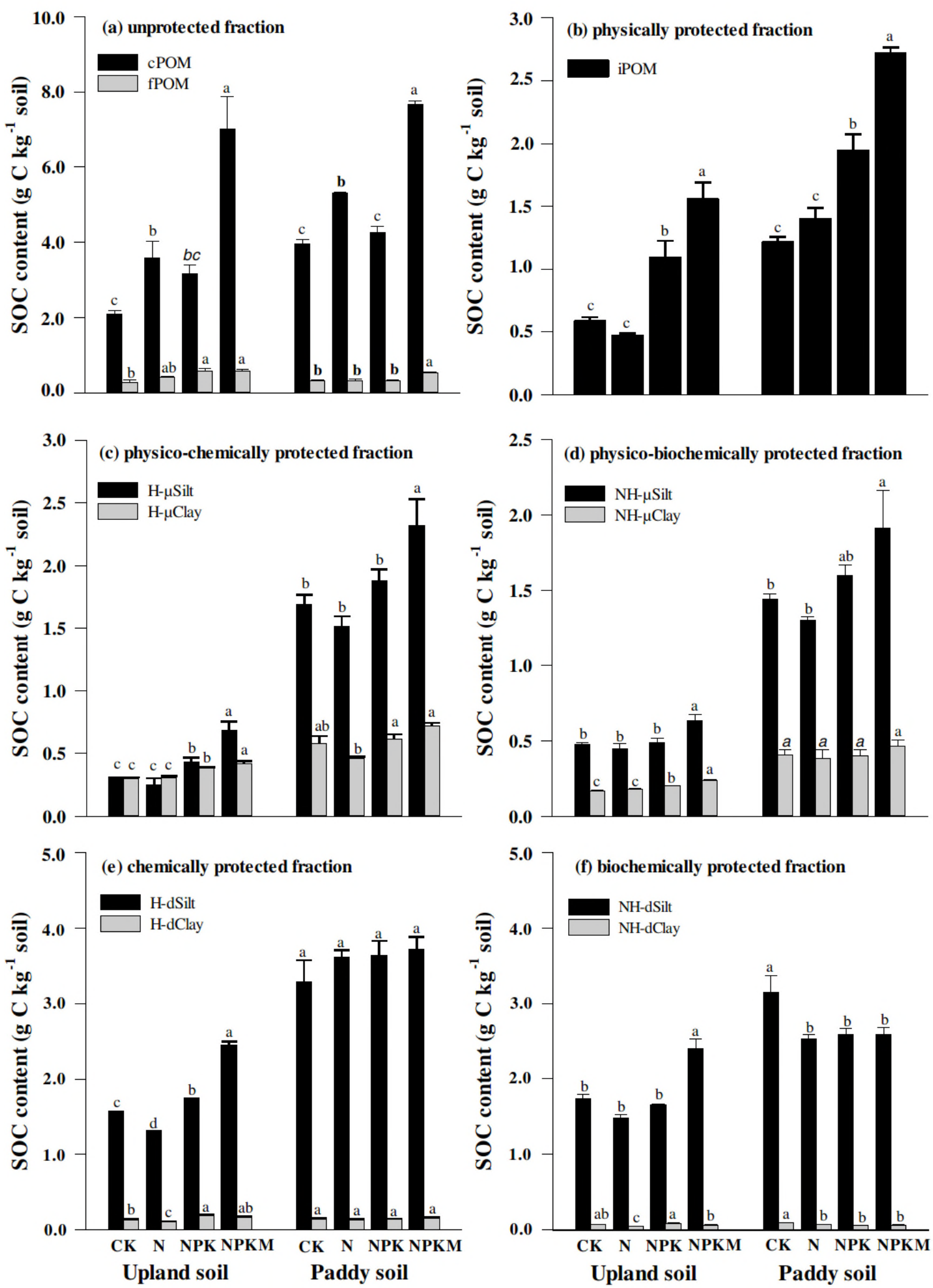

Fig. 2 Soil organic carbon (SOC) content in functional soil organic matter (SOM) fractions under longterm fertilization in upland and paddy soils. Different lower-case letters indicate significant differences $(p<0.05)$ among treatments within each site. Error bars represent standard error of the mean $(n=3)$. $\mathrm{CK}$, control; N, N fertilizer application; NPK, N, P, and K fertilizer application; NPKM: combined N, $\mathrm{P}$, and $\mathrm{K}$ fertilizer and manure application. 

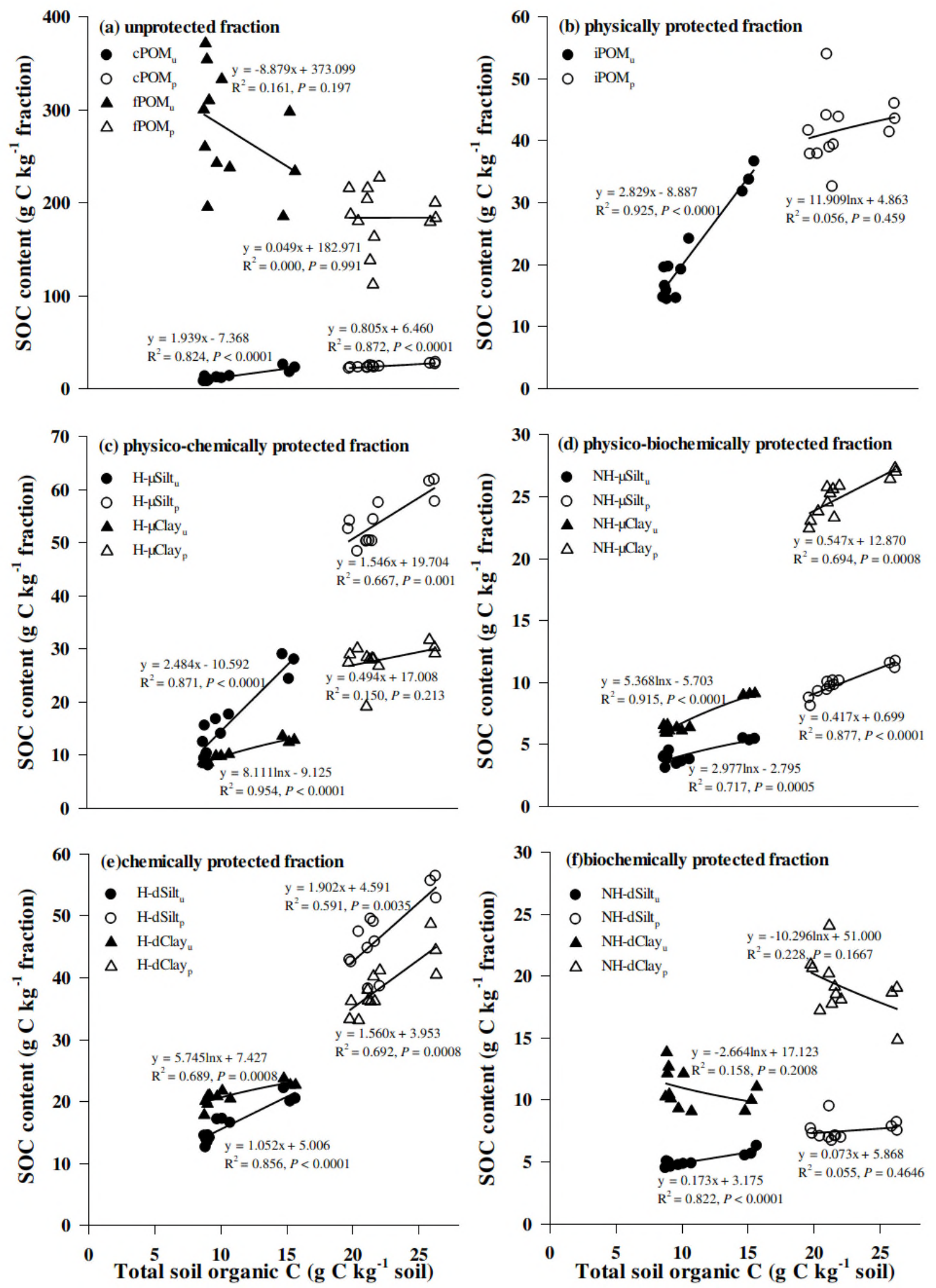

Fig. 3 Relationship between soil organic carbon (SOC) content within functional soil organic matter (SOM) fractions and total SOC under long-term fertilization in upland and paddy soils. The subscript letters $u$ in legends refers to the fractions in upland soil and $p$ refers to the fractions in paddy soil. 